\title{
Cartagena: ciudad monumental para el turismo y discurso glorificador en la prensa local de mediados del siglo $\mathrm{XX}^{*}$
}

Isela Caro Hernández ${ }^{1}$

Universidad de Cartagena

\section{Resumen}

En este texto nos proponemos examinar las imágenes e imaginarios sobre ciudad que se establecieron y circularon en la prensa de Cartagena de Indias a mediados del siglo XX. Estableceremos las distinciones conceptuales necesarias entre imágenes urbanas e imaginarios como punto de entrada al análisis del discurso periodístico, y veremos cómo este discurso, fundamentado en los intereses y expectativas de las élites, recrea una imagen urbana desde los tópicos de modernización, progreso y destino turístico.

Palabras clave: ciudad, imaginarios, imagen urbana, mediaciones, modernización.

\section{Abstract}

In this article we will examine the images and the imaginaries that were created about the city circulating in the local newspapers in Cartagena de Indias about the middle of twentieth century. We will work on the necessary conceptual distinctions given between urban images and the imaginaries, as starting point to the analysis of journalistic discourse, and observing how this discourse, founded on the interests and the expectations of the elites, recreates a urban image by promoting the concepts of modernization, progress and touristic destinations.

Key words: city, imaginaries, urban image, mediations, modernization.

\footnotetext{
* Cartagena in the middle of twentieth century: The monumental city as a touristic destination and the glorious discourse coming from the local newspapers.

Recibido: Marzo, 2011 - Aprobado: Abril, 2011.

${ }^{1}$ Profesional en Lingüística y Literatura de la Universidad de Cartagena. Magíster en Historia de la Universidad Pedagógica y Tecnológica de Colombia (UPTC). Docente del programa de Lingüística y Literatura de la Universidad de Cartagena. e-mail: isecaro@gmail.com
} 
Cartagena de Indias siempre ha afrontado las contradicciones inherentes a la oposición entre sus condiciones materiales y una ansiada constitución como destino turístico. Esto determinó que, en el discurso promovido por las élites de la ciudad, especialmente presente en la prensa local, se debatiera la necesidad de "modernizarla", adecuarla a las exigencias del turismo internacional, modificar su entorno físico, si era necesario -por ejemplo, la destrucción parcial de sus murallas-, y al mismo tiempo, la necesidad de encubrir las profundas desigualdades sociales presentes desde los tiempos de la Colonia ${ }^{2}$.

Como consecuencia, en la prensa se recrearon de manera permanente noticias que denunciaban los problemas de servicio público e infraestructura. La queja casi siempre estaba acompañada por la preocupación del "progreso". Éste, como se sabe, construye su sentido partiendo de una constelación de ideas como futuro, desarrollo o evolución (pilares constitutivos de Occidente, que buscan la perfección, no espiritual, sino material, bajo el diseño de la ciudad hecha a base de cálculos y tecnologías). Aunque los problemas urbanos en la historia de Cartagena han sido el pan de cada día ${ }^{3}$, los anhelos de progreso estuvieron siempre presentes en el discurso. En un artículo de El Universal de 1952 leemos:

Invitamos a todas las entidades públicas y privadas de la ciudad, más directamente interesadas en su progreso y bienestar, para que aúnen esfuerzos en un vigoroso movimiento de opinión popular y procuren sacar de este deleznable terreno de incertidumbre $\mathrm{y}$ vacilaciones, los problemas que hoy afrontan las Empresas Públicas municipales, sin que todavía haya la esperanza de que se le ponga remedio a un estado de cosas que ya es insostenible y que no debe prolongarse por más tiempo, como asílo exige el decoro de Cartagena (El Universal, Cartagena, 9 de marzo de 1952).

Podemos inferir que la idea de progreso era tan sólo una expectativa que, además, se convertía en un argumento de fuerza para conminar a las entidades públicas y privadas a formar un movimiento de opinión popular. Tema en el cual insistió mucho la prensa, presentando una

\footnotetext{
2 Estos asuntos están ampliamente documentados en los trabajos de Guerrero (2008), Vidal (1997) y Ávila Domínguez (2008).

3 Al respecto puede hacerse un seguimiento detallado en Giaimo Chávez (2000) -particularmente sobre la tensión entre los intentos de planeación urbana y sus dinámicas de crecimiento sin control-.
} 
queja permanente sobre la falta de una actitud crítica por parte de los cartageneros: "Uno de los defectos, por no decir vicios de que adolece generalmente la ciudadanía cartagenera, es el de mantenerse sin la necesaria y conveniente solidaridad de intereses, como indiferente ante todo aquello que más le afecta vitalmente" (El Universal, $8 \mathrm{de}$ octubre de 1950).

Los esfuerzos constantes que exigía el desarrollo para hablar de una sociedad avanzada tendrían como contratiempo no sólo la discontinuidad de sus políticas urbanas, el personalismo de los administradores o la exclusión social, sino también cierta pasividad de sus ciudadanos. Podría hablarse, sin embargo, de coyunturas en la que los cartageneros se levantaron para dejarse oír. A través de la prensa, por ejemplo, se muestra un rostro distinto de la población. En el caso de la supresión del ferrocarril Cartagena-Calamar, encontramos el siguiente titular: "Una vigorosa campaña para evitar su suspensión debe adelantarse. Por todas las fuerzas vivas de la ciudad. -Nueva batalla por el progreso de Cartagena" (El Universal, 25 de octubre de 1950).

En otro momento la prensa publica un dibujo que alude al levantamiento de los rieles, cuando indudablemente la presencia de este medio de transporte no sólo denotaba comunicación, sino que también representaba para los cartageneros un fuerte antecedente de desarrollo:

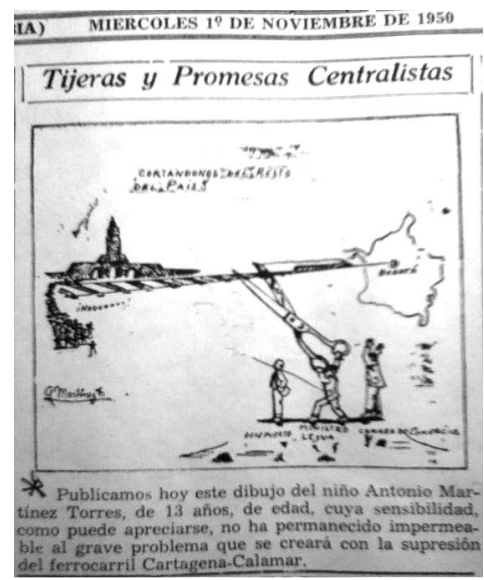

El Universal, Cartagena, 1 de noviembre de 1959

Esta publicación muestra el dibujo titulado: "Cortándonos del resto del país", supuestamente realizado por un niño ${ }^{4}$. La imagen de

\footnotetext{
${ }^{4}$ Si bien hemos examinado con atención el texto de Burke (2005), salvo ésta, todas las demás imágenes usadas en nuestro trabajo sirven para ilustrar los textos de los titulares, notas de prensa y noticias estudiadas.
} 
la Torre del Reloj, que está hacia la izquierda del plano, simboliza Cartagena ${ }^{5}$. Se representa, así mismo, el camino del ferrocarril que va desde la Torre, apuntando hacia la derecha del croquis de Colombia (hacia el centro, que es Bogotá). La explicitación del nombre de esta ciudad se conecta con la frase "promesas centralistas". Notamos una multitud simbolizando el grito de "NO", y toda la ironía concentrada en la representación del defensor del puerto, el Ministro de Obras Públicas, quien carga la gran tijera, y del representante de la Cámara de Comercio. Queda ilustrada de este modo la trascendencia de la desaparición del ferrocarril Cartagena-Calamar.

El argumento de defensa giraba en torno a la idea de que el ferrocarril era la prolongación hacia el río Magdalena desde el terminal marítimo: vital recurso terrestre para cargas pesadas y una muy importante fuente de empleo. Se sostenía, además, que la canalización del Dique debía ser complementaria y no contraria al ferrocarril. En el titular "Cartagena necesita su ferrocarril" (El Universal, Cartagena, 1 de noviembre de 1950$)^{6}$ se citaba al presidente de Fenalco, Vicente Martínez Martelo, quien apoyaba esta idea afirmando que en Estados Unidos (ejemplo de modernización) se presentaban paralelos los servicios de río, carretera y ferrocarril. Ávila Domínguez lo ilustra:
Una de las manifestaciones más evidentes del resentimiento de la actividad económica es que el ferrocarril, símbolo del progreso y el proceso de modernización económica vivido entre finales del siglo XIX y comienzos del XX, dejó de funcionar en 1950. El cese de operaciones de este importante medio de trasporte significó la pérdida de competitividad comercial de la ciudad con otros centros urbanos, pérdida que incrementó los bajos indicadores de producción industrial y generación de empleo. Para entonces, el estancamiento de la ciudad era

\footnotetext{
${ }^{5}$ Ávila Domínguez explica detalladamente los sentidos de la simbolización de Cartagena de Indias con la Torre del Reloj: "La utilización de la Torre responde al propósito de la Corporación Turismo Cartagena de Indias y demás agentes locales de posicionar a la ciudad como un destino para el turismo cultural, aprovechando sus recursos históricos y patrimoniales. [...] La Torre es, pues, fachada y puerta de entrada a la ciudad antigua. De hecho, en mapas y otros materiales elaborados de carácter turístico es marcada como una de las primeras estaciones del recorrido. Apenas se atraviesa su puerta principal, abierta desde su construcción en 1601, aparece a la vista, en la plaza de los coches, una estatua de Pedro de Heredia, fundador de Cartagena." (2008: 104).

${ }^{6}$ Una breve y precisa síntesis sobre todo este proceso del ferrocarril se puede encontrar en Sparrow (2011).
} 
más o menos proporcional al crecimiento de otras ciudades como Bogotá, Medellín o Barranquilla (Ávila Domínguez, 2008: 69).

La prosperidad, los avances y el auge económico de los Estados Unidos se habían convertido en el camino a seguir, pero el desafío del progreso para Cartagena se entorpecía con los problemas estructurales de la misma. En la década de los cincuenta le era familiar a la prensa publicar informes como este:

Sin que todavía haya sido resuelto definitivamente el problema de la planta eléctrica que tantos males le ha ocasionado a la ciudad, nos encontramos de manera intempestiva enfrentados a una nueva calamidad de no menos graves repercusiones: los trastornos ocurridos en el suministro de agua ocasionados, según las empresas públicas, por obstrucción en la bocatoma de Gambote y a consecuencia de las obras de dragado que se llevan a efecto en el canal del Dique (El Universal, 9 de marzo de 1950).

Así la ciudad que hoy resplandece por su fragmento de ciudad turística ${ }^{7}$, en los años cincuenta se destacaba en los medios por sus permanentes contratiempos, por problemas de infraestructura y de servicios públicos. Pero esto no puede ser visto sólo como cosa del pasado, ya que para ella son "tradición" los problemas de esta índole. Para mayor ilustración miremos las siguientes imágenes:

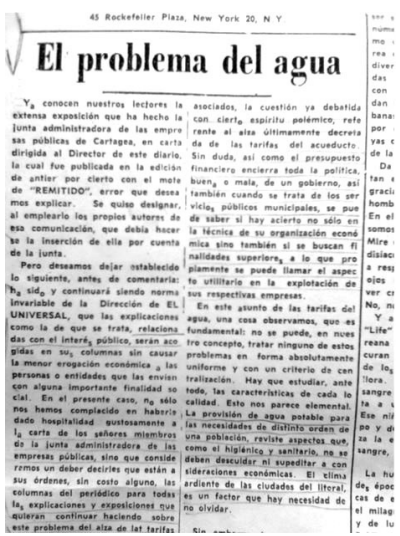

El Universal, Cartagena, 8 de octubre de 1950

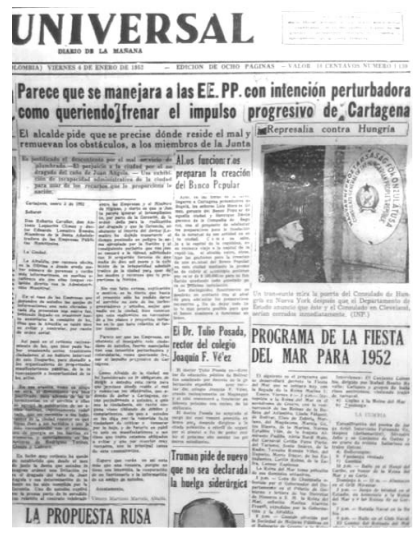

El Universal, Cartagena, 4 de enero de 1952

\footnotetext{
${ }^{7}$ Sobre el turismo y la exclusión en la ciudad de Cartagena, véase Cunin $(2007,2003$ y 1999). Así mismo, también los citados trabajos de De Ávila Pertuz (2008), Ávila Domínguez (2008) y Carrillo Romero (2011). Sobre pobreza en Cartagena desde el punto de vista económico, Pérez \& Salazar Mejía (2007).
} 


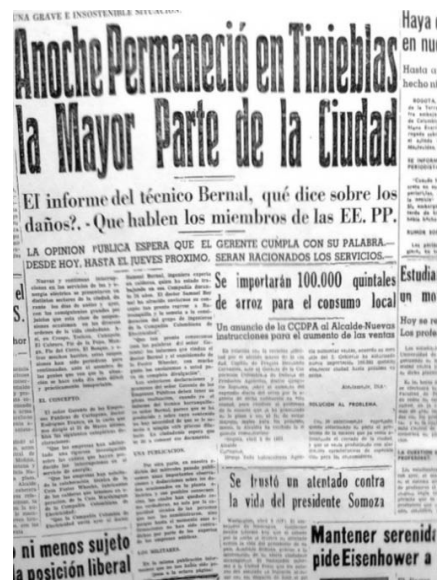

El Universal, Cartagena, 6 de abril de 1954

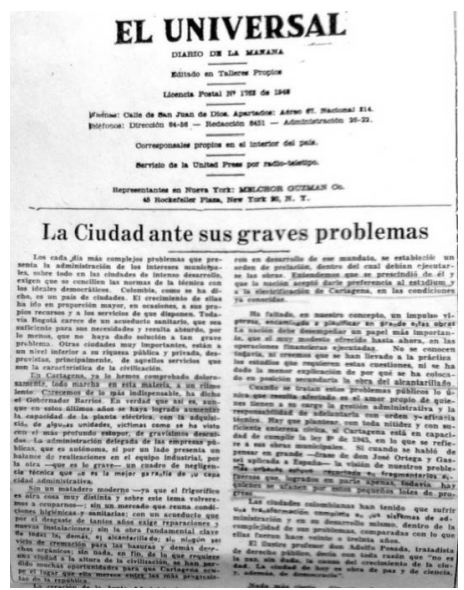

El Universal, Cartagena 13 de abril de 1954

Una vez establecido el imaginario de la ciudad como búsqueda de la objetivación del progreso, éste se convirtió en el esquema para concebir el espacio urbanístico (uno que debía adecuarse para el desarrollo armónico de las sociedades). La ciudad debe ser el espacio físico donde los sujetos desarrollaran todas sus facultades de modo integral, contando con una infraestructura moderna para prestar los bienes y servicios que corresponden a las necesidades básicas, espacio privado para el desarrollo personal y espacio público para garantizar la convivencia ciudadana. Esto permitiría el acceso a lo económico, a lo cultural, a lo político, y la tecnología sería el motor para impulsar una modernización permanente ${ }^{8}$.

En aras de aplicar la fórmula, las ciudades latinoamericanas se encontraron con desafíos distintos a Europa y Estados Unidos: entre otros la heterogeneidad cultural, donde se daba la presencia de culturas a las que se les ha llamado pre-modernas, porque sus sociedades y estilos de vida se conciben de modos distintos a los llamados grupos étnicos, que no encajarían en el anterior esquema de desarrollo. Por otra parte, a pesar de que los cruces han sido inevitables, las jerarquizaciones sociales subrayaban las diferencias entre sectores populares y sectores de élite heredadas del esclavismo y la estigmatización sociocultural sobre los indígenas. Todo esto llevó a planear una ciudad con mayor atención a los espacios privados y que contrastaban con el otro lado de la ciudad pobre, periférica, que creció en dimensión física, mas no en progreso (combinación

\footnotetext{
${ }^{8}$ La estrecha relación entre la concepción del espacio y las ilusiones de progreso de la modernidad pueden verse en Ortiz (2000).
} 
de planeación oficial y autoorganización muchas veces ilegal. Diversos barrios de Cartagena cuentan su historia como efecto de una invasión).

Establecer el modo de una economía moderna fue también un proyecto a medias. Tanto así que la economía informal cada vez se hizo más resistente. Las ciudades latinoamericanas, lejos de ser espacios de equilibrio, se desbordaron en su universo sociocultural. La estratificación de los sectores populares superó el esquema piramidal y el esquema triétnico no bastó para dar cuenta del espesor de la cultura. En la pregunta que se hace Mónica Lacarrieu (2007), en su artículo "La 'insoportable levedad' de lo urbano", sobre qué rol juegan las diversas manifestaciones culturales en la construcción de imágenes e imaginarios urbanos, se muestra cómo en los estudios contemporáneos de ciudad se presenta el interés, más que en las edificaciones mismas, en las vivencias y prácticas de los ciudadanos. Esto se debe a que se reconoce que las prácticas desarrolladas en el espacio son el resultado complejo y conflictivo de imágenes e imaginarios y representaciones sociales. De aquí que se haga más importante la producción y apropiación del espacio público y tomen mayor sentido los modos de percibir la ciudad: el olor, la degustación, la observación, la posibilidad de tocar las cosas, de encuentros y desencuentros.

Escribe la autora: "La ciudad contemporánea ya no es la ciudad sin cuerpo, sino la ciudad descorporeizada o sin aparente cuerpo, en la que, mientras lo material pierde peso específico, el sentido de lo simbólico, lo experiencial y sensorial toma cuerpo, se dispone físicamente" (48). Por el contrario, en los estudios que anteceden esta perspectiva se pensaba la ciudad desde su pesadez material (el centro de atención estaba en aquello que daba forma a la ciudad industrial). Lacarrieu, citando a Shanti Pillai, habla de la ciudad sin cuerpo, es decir, sin los sujetos que la habitan: "entidad corpórea marcada por la monumentalidad que invisibilizaba la levedad de otros espacios, relatos y mapas construidos por los sentidos y prácticas de los ciudadanos" (48) .

En la década de los cincuenta (periodo de nuestro análisis), las imágenes forjadas sobre Cartagena de Indias estuvieron basadas

\footnotetext{
${ }^{9}$ La "dimensión física monumentalizada" de Cartagena se evidencia en los múltiples trabajos dedicados a sus construcciones militares y monumentos históricos en general. A manera de ejemplo, pueden citarse los de Marco Dorta (1951), Serrano Álvarez (2004) y Lizcano Angarita \& David Daccarett (2004). Ávila Domínguez (2008: 26) referencia diversos trabajos.
} 
en la monumentalidad. Básicamente se buscaba resaltar el paisaje urbano y el valor del patrimonio histórico. Miremos cómo esto se hace evidente en una noticia publicada en 1946, donde se aluden los comentarios de un dirigente del comercio en Bolívar publicados en la revista Semana:

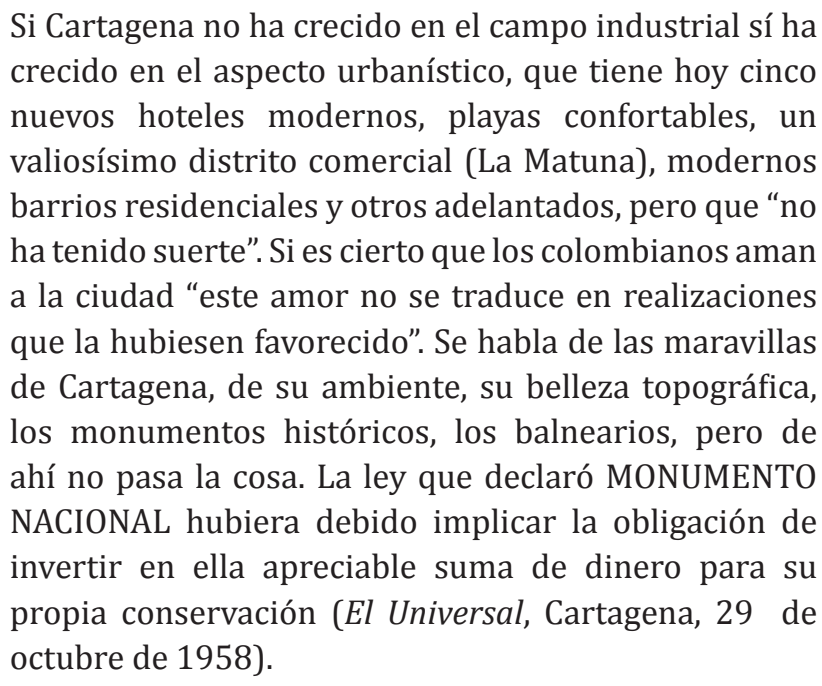

Mostrar el crecimiento físico de la ciudad era mostrar la cuota de progreso que ayudaba a forjar la imagen de una ciudad digna de visitar. Los habitantes y su universo cultural no se promovían en dicha imagen. El progreso se concentraba en aquellos lugares relacionados con el patrimonio histórico y con los barrios privilegiados: las marcas desde las cuales se constituía la expresividad de la ciudad estaban elaboradas, en gran parte, bajo la evocación de su "glorioso" pasado. Al ausentar a los sujetos de las representaciones de la ciudad, inevitablemente se dejó de ver la dimensión cultural. Lo que se resaltaba era el monumento, ya que como dice Mónica Lacarrieu (2007), el "artefacto material encumbrado en calidad patronizable está ligado al prestigio que obtiene el pasado" (53). Desencadenante de un proceso de cristalización de imágenes como el de la célebre y hegemónica: "Cartagena, el corralito de piedra".

Así se ha llegado a una organización de la ciudad a partir de esa imagen legitimada, que disciplina y da coherencia al espacio a través de una doble actuación: la redención y purificación del territorio, y la monumentalizarían de la ciudad por "la implantación de monumentos de fuerte arraigo simbólico que puede disminuir la tendencia de disgregación del vecindario 
de las grandes urbes al tener un punto de referencia para reconocerse [...]" (Delgado, 1998, citado por Lacarrieu, 2007: 54).

Otra pauta que nos da la autora es cómo los espacios que se tornan históricos y culturales se piensan como lugares de neutralización de poder, ya que se definen en tanto proyectos urbanos, transmisores de valores y comportamientos. Se define así qué forma de apropiación del espacio es autorizada y qué rasgos culturales deben asumirse, cuáles dan límite de lo propio y de lo ajeno, de lo permitido y lo prohibido, de lo tolerable y lo intolerable, de lo nombrable y lo innombrable. Las imágenes que constituyeron el sentido "oficial" de Cartagena no son más que un conjunto de imágenes estereotipadas que han ocultado otras: las de la exclusión y la desigualdad (Cf. Deávila Pertuz, 2008; Guerrero Palencia, 2008; Ávila Domínguez, 2008).

Cartagena tuvo el desafío de constituirse en ciudad moderna, ya que Colombia estaba en proceso de convertirse en un país de ciudades. Pero esto no sería asunto solo de división político-administrativa, o de modernización económica e industrial. El hecho de que cada ciudad tuviera el mismo propósito implicó una inevitable lucha de jerarquías sociales. En este caso, las ciudades y otras formas de territorio, como departamentos, municipios y distritos, pueden verse, por distintas razones, como categorías sociales. Las ciudades, en tanto ciudades, adquieren mayor legitimidad que las provincias: hubo una repartición desigual de diferentes especies de poderes. La ciudad puede verse así en términos de posición social, y sus dinámicas pueden ser entendidas desde la noción de campo de Bourdieu (1990), como "espacios estructurados de posiciones (o de puestos) cuya propiedad depende de su posición en dichos espacios y pueden analizarse en forma independiente de las características de sus ocupantes (en parte determinados por ellas)" (135). ${ }^{10}$

De este modo, la ciudad es vista como una posición que adquiere privilegios cuando es vista como ciudad industrial, ciudad capital, o como lo es actualmente Cartagena: Distrito Turístico. Bourdieu establece que la estructura del campo:

Es un estado de la relación de fuerzas entre los agentes o las instituciones que intervienen en la lucha o, si ustedes prefieren de la distribución del capital

${ }^{10}$ Discusiones ampliadas y numerosas aplicaciones de estas ideas están en Bourdieu (1997) y en Bourdieu \& Wacquant (1995). 
específico que ha sido acumulado durante luchas anteriores, y que orienta las estrategias ulteriores. Esta misma estructura, que se encuentra en la base de las estrategias dirigidas a transformarlas, siempre está en juego: las luchas que ocurren en el campo ponen en acción al monopolio de la violencia legítima (autoridad específica) que es característico del campo considerado, esto es, en definitiva, la conservación o subversión de la estructura de la distribución del capital específico (136).

Hablar de posiciones jerárquicas es hablar en términos simbólicos con fuertes incidencias en el espacio físico, ya que las dinámicas sociales en su mayoría ocurren en espacios concretos. En tanto espacio simbólico, la ciudad se instala como centro de poder al establecerse en ella un sistema urbano que trae consigo diferentes tipos de desarrollos, especialmente industriales y económicos. Entre los años cincuenta y sesenta, la urbanización aceleró sus ritmos, y ciudades como Medellín generaron un impacto de progreso gracias a sus avances en la estructura física, la red de transportes y los servicios públicos (en sintonía con su crecimiento industrial). De igual modo ocurrió también con Cali, Barranquilla, y en menor medida, con Bogotá ${ }^{11}$.

En la primera mitad del siglo veinte, Cartagena no ocupaba un lugar privilegiado, como había sucedido durante la Colonia, donde le eran muy favorables sus vínculos directos ${ }^{12}$ con la Corona (centro de privilegios y capital simbólico) ${ }^{13}$. Cartagena era la plaza fuerte del poder colonial español en América, y esto le significaba la prosperidad económica con la que ya no contaba en la primera mitad del siglo veinte. En este tiempo la meta por alcanzar era la

\footnotetext{
${ }^{11}$ Para el caso detallado de las capitales departamentales del Caribe colombiano y la ciudad de Magangué, véase Abello Vives \& Giaimo Chávez (2000).

12 "El objeto y razón de ser de las luchas son estos bienes (capital económico, capital cultural, capital social, capital simbólico), recursos o capitales producidos específicamente en cada campo [...] Capital social: son los recursos y posibilidades actuales y potenciales ligados a la posesión de un red durable de relaciones sociales, expresadas por intermedio de la pertenencia a grupos [...] Pertenecer a grupos de poder, tener "relaciones" con gentes que poseen diferentes formas de capital, permite el intercambio de "favores" y "servicios". Capital simbólico: es la acumulación de todas las especies de capitales posibles, que generan crédito y autoridad en los agentes que la poseen" (Téllez Iregui, 2002).

${ }^{13}$ El papel de Cartagena en el periodo de la Independencia es contradictorio, dado los recelos mutuos en las relaciones con las élites provinciales. Véase Abello Vives, Alberto \& Bassi Arévalo (2005), Conde Calderón (1994) y Múnera Cavadía (1998).
} 
industrialización, el comercio, pero la ciudad no pasó de pequeños intentos. Lo que le permitió alguna visibilidad fue su connotación de ciudad cultural (contaba dentro de la región con una Universidad importante y algunos colegios de secundaria).

Para que funcione un campo, dice Bourdieu (1990), "es necesario que haya algo en juego y gente dispuesta a jugar, que esté dotada de los habitus que implican el conocimiento y reconocimiento de las leyes inmanentes al juego, de lo que está en juego" (136). De este modo se presuponen unos acuerdos que marcan aquello por lo que vale la pena luchar, produciendo una creencia en el valor de lo que está en juego. El progreso es la condición para ser ciudad, es su propósito central: la modernización del espacio, avenidas, arquitecturas modernas dotadas de servicio, zonas comerciales, industriales. Podríamos considerar que alcanzar este propósito se adaptaría a lo que entendemos por "illusio" (para Bourdieu, centro de interés de cada campo o adhesión originaria al juego, fundamentado por una creencia). Ilusión de realidad colectiva, en la que ningún miembro se resiste a la ficción, lo cual garantiza que vale la pena jugar y reproducir el juego. Veamos cómo muchos cartageneros de mediados del siglo $\mathrm{XX}$ compartieron la creencia en el progreso:

Este destino intelectual lo ha seguido manteniendo en la vida de la República, pero es preciso hacer los mayores esfuerzos porque no desaparezca la guía espiritual de la ciudad, y que su fisonomía de centro universitario y cultural se mantenga al lado de los indispensables avances que debe hacer el progreso en la vida de la ciudad. Y es que en verdad es preciso adoptar en esta cuestión una posición de equilibrio, que es la más racional y sensata en este caso. Al progreso no puede detenérsele con razones y no sería explicable que se estableciera una romántica superstición del pasado [...] Así, ha sido posible que Cartagena haya avanzado en muchos aspectos de su existencia hasta ponerse al nivel de las grandes ciudades modernas, pero sin que pierda esa fisonomía histórica que tanta fama le ha dado [...] Todos estos factores sociales deben ser aprovechados en los planes de progreso de la ciudad, especialmente en lo que hace al turismo, el cual tiene en ella uno de sus veneros inagotables, y que debe ser impulsado mediante una organización racional, eficaz y dinámica (El Universal, Cartagena, 9 de noviembre de 1958). 
Hubo inevitablemente una apuesta por el progreso de parte de los cartageneros, al mismo tiempo que un apego a su pasado glorioso. La primera estaba ligada a los cambios materiales de la ciudad, a su trasformación urbanística, como hechos pragmáticos que disponían de algún desarrollo económico, y el segundo a una construcción de sentido de su presente a partir del pasado. El tono del discurso con el que se desarrolla esta nota periodística no es más que una búsqueda de la legitimidad de un presente modernizador y de un pasado que se enaltece. Como lo expresa Raúl Román (2001), a propósito de la utilización de los referentes históricos para la legitimación y el reconocimiento del presente:

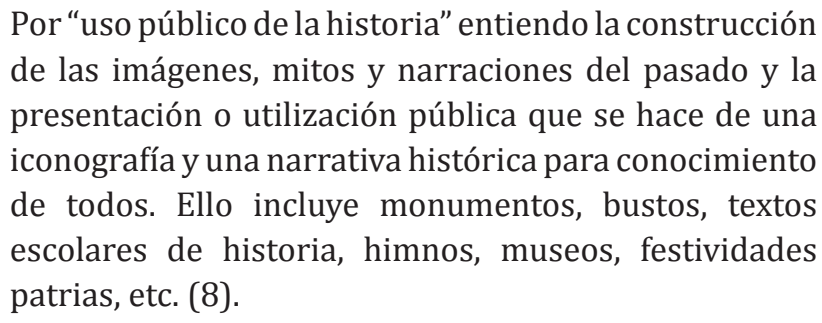

Para entender las formas básicas con las que se organizan las relaciones sociales, culturales y simbólicas, hay que tener en cuenta que es un sistema de fuerza y de sentido entre los grupos sociales, donde lo simbólico corresponde a un ámbito central del poder, y las luchas están determinadas por la desigualdad de las fuerzas en tensión (Vizcarra, Fernando, 2002: 55-68). Los anhelos de Cartagena por crecer, aun con todos sus contratiempos, fueron alimentados por los modelos de las otras ciudades grandes, siendo que ésta era una ciudad al margen en diferentes aspectos: políticos, económicos, industriales, de cobertura de servicios básicos, entre otros. Y entender la estructura del campo en sus relaciones de poder, supone analizar simultáneamente dichos aspectos, que al mismo tiempo podríamos verlos como capitales (simbólicos, pero también sociales y económicos) que cada ciudad detenta o aspira detentar. En la dinámica de los campos se da la lucha entre pretendientes y dominantes.

En los años cincuenta la ciudad estaba en su posición de pretendiente. Apenas empezaba a asomarse un progreso por fragmentos. Y en la búsqueda de "capitales" comunes entre ciudades fue necesario desarrollar "estrategias": recursos y acciones que permitieran establecer alianzas y legitimar argumentos y visiones. Como las luchas entre posiciones corresponden a normas establecidas (explícitas o implícitas) que transforman y conservan los sistemas dominantes de las relaciones sociales, las estrategias no aseguran la obediencia 
mecánica a la regla explícita (o a lo que se pueda percibirse como una regla implícita). Como el juego está desigualmente repartido, queda la libertad de invención y de improvisación, lo cual permite infinidad de jugadas (Téllez Iregui, 2002).

En una lucha entre pretendientes (ciudades como Cartagena) y entre dominantes (como Barranquilla) por la obtención de capitales específicos, donde apostaban por una misma "illusio", vemos claramente que el turismo fue una estrategia para la ciudad pretendiente. La Cartagena de Indias, dominante de su pasado colonial, expiró con el sitio de Morillo, como ha sido documentado ampliamente. La ciudad que languideció a lo largo del Siglo XIX ni siquiera pudo aspirar a la condición de pretendiente a un nuevo ascenso. Sólo a finales del siglo XIX y comienzos del XX empezó la búsqueda de progreso, desarrollo material y redención económica, también ampliamente documentada. Y el capital cultural, en la forma de capital histórico, vino a constituirse como simbólico en gradual proceso de valorización, hasta devenir en el eje de las estrategias de reconocimiento de la nueva ciudad pretendiente de mediados del siglo $\mathrm{XX}^{14}$.

Fue a través de esta estrategia que Cartagena logró una nueva visibilidad. Su recursividad ha estado en sus diferentes intentos por convertirse en ciudad turística, en hacerse reconocer por su carácter histórico y recursos naturales, para así alcanzar una transformación urbanística. Podemos considerar que dicha estrategia se alcanzó con diferentes jugadas, como agenciar reconocimientos institucionales: la Ordenanza $\mathrm{N}^{\circ} 78$ del 30 de mayo de 1947, emitida por la Asamblea Departamental de Bolívar y aprobada por el honorable Concejo Municipal de Cartagena, para la organización de la industria del turismo (Vidal, 1997: 83); el título de Patrimonio Nacional de Colombia, el 30 de diciembre 1959; el consagrarse como Patrimonio Histórico y Cultural de la Humanidad el 28 de mayo de 1984 a través de la Unesco, y hasta convertirse en la cuarta maravilla de Colombia en el 2007, por su arquitectura militar. Otras fichas movidas estratégicamente fueron el fortalecimiento de sus relaciones internacionales y su promoción de imagen turística

\footnotetext{
${ }^{14}$ Sobre las distintas etapas de las duraderas crisis de Cartagena, véase, por ejemplo, el citado Múnera Cavadía (1998), Zambrano Pantoja (2000), Meisel Roca (1999), entre otros. Sobre el uso del capital histórico para el posicionamiento turístico, los citados Vidal (1997), Guerrero Palencia (2008), Deávila Pertuz (2008) y Ávila Domínguez (2008). En este último se analiza el paso de la imagen de ciudad turística "de sol y playa", dominante hasta los años setenta del siglo XX, a la imagen del capital histórico (el énfasis preferente en la escenificación de la "ciudad histórica"), convertido en atractivo para el "turismo cultural."
} 
a través de diversos medios (Cf. Ávila Domínguez, 2008), con papel preponderante de la prensa. Miremos algunos ejemplos:

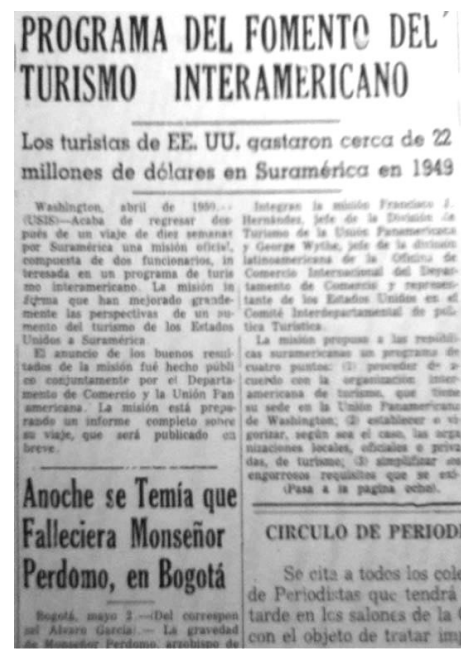

El Universal, Cartagena, 3 de marzo de 1950

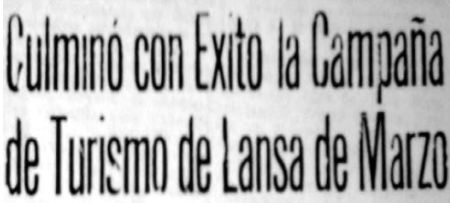

Invitó a doña Mercedes Dager a Pereira-Da facilidad de viaje a la directicva del CPC.-

Con singular esito cuiming la empresa de los periodistas. Se ha campana de turimo que la presti prescupado siempre por contribuir giosa empreas de aviación Lana al desarrollo de todas las iniciat. puso en prictica furante el pasado vas de los diaristas colombianos. mes de marzo. Esta iniciativa tuvo Ahora, precisamente, acaba de ta. fervora acoeida ya que fue un cllitar el transporte de las distiatas verdadero estimulante para el tu. delegaciones que tomarin parte en rismo colomblano. Fueron numero- el congreso de prensa y ea el toras las personas que hicieron uso neo de futbol que teadra del importantle programa de lin de

jemana que Lansa ilevo a las leili con Cartagena

culminacion. Este prograna cimien.

io ie las ciudades colombianas o in Como es bien sabido, recientemen to de las clades col intereambio te fue fundado el Cireulo de Perio untre las distintas regiones del pais. distas de Cartagena. La empresa

\section{El Universal, Cartagena, 4 de} abril de 1950

\section{Mañana se Inauguran en Bogotá Programas Radiales Pro-Cgena.}

El grupo de enturlantas jovenes cartageneros que en Becola adelas tan una muy bien diricida campasa de propaganda en faver be la cia dad $y$ de sus grandes obras, lanage rark mañana a las 8 de la nocbe los grandes programas de radie gu continuarán trasmitiendose todo Los domingos por la Radio Contibe tal de squella cludad a csa misen. hora,

E. este su primer Brograma. if

El Universal, Cartagena 27 de mayo de 1950
LA JUNTA DE TURISMO SIGUE LABORANDO POR SU FOMENTO

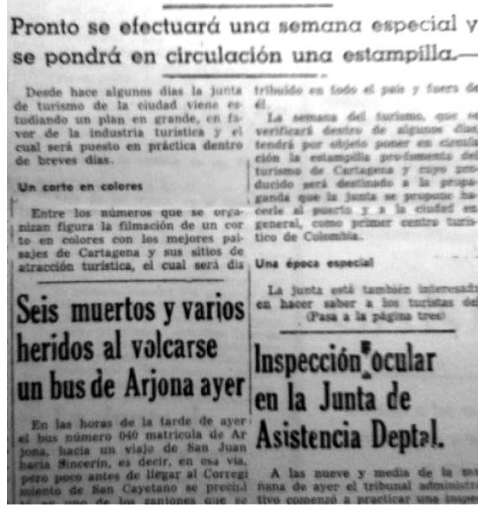

El Universal, Cartagena 5 de julio de 1950 


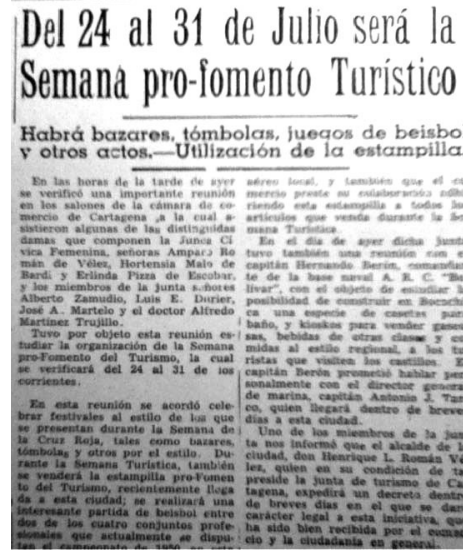

El Universal, Cartagena, 6 de Julio de 1950

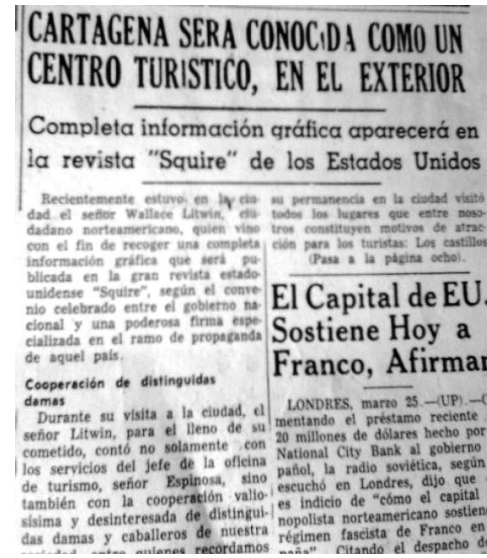

El Universal, Cartagena, 26 de Marzo de 1950
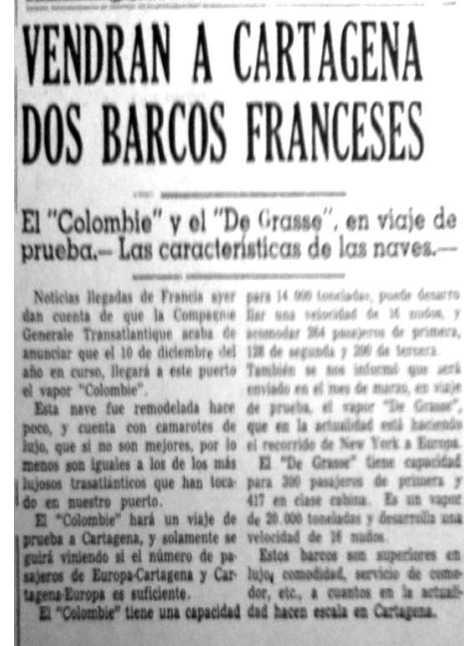

El Universal, Cartagena, 15 de julio de 1950

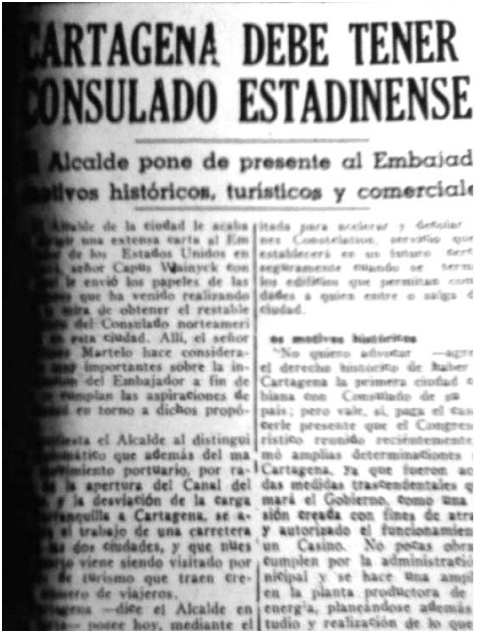

El Universal, Cartagena, 20 de enero de 1950

Al seguir atentamente los anteriores titulares vemos cómo la estrategia se puso en marcha. "Campaña”, "fomento", "propaganda”, son palabras que muestran el interés por promover la ciudad en el resto de país y en el extranjero. Evidencia, además, que sus circuitos de información estaban dando resultados. Está aquí el itinerario de las distintas visitas entre norteamericanos y franceses que no sólo llegaban en barcos, sino en aviones. Es clara la idea, así mismo, de la importancia del apoyo internacional, y para completar dicha estrategia, las autoridades locales expresan la necesidad de un consulado estadounidense. 
La condición turística no sólo refuerza la economía de una ciudad sino que también le permite ser reconocida. Las tensiones que se dan en las relaciones sociales no son más que para poder hacerse visible, hacer presencia; ser un interlocutor. En lo social, el espacio no es homogéneo, las jerarquías son inevitables y la legitimidad es un precio que se paga, ya sea con capitales heredados o adquiridos. Lo que iguala a todos es la apuesta en el mismo juego; pero dicha tensión se da por la repartición desigual de las legitimidades. Cartagena actualmente es vista con ojos de privilegios: resulta ser una atracción para el resto del país y para algunas zonas del exterior. Sin forzar las cosas, podríamos decir para Cartagena lo que Saida Palou Rubio (2006) plantea para Barcelona:

\begin{abstract}
Las molestias causadas por la masificación en determinados espacios públicos de la ciudad, los procesos de gentrificación que sufren algunas zonas, la banalización de algunos símbolos relacionados con la identidad de la ciudad o la especialización del comercio alrededor de los iconos turísticos, son cuestiones que preocupan a la población y ante los cuales hay que asumir serias gestiones. (79)
\end{abstract}

\title{
Bibliografía
}

Abello Vives, A. \& Bassi Arévalo, E. (2005). "Entrevista a Aline Helg: Cartagena no unía durante la Independencia”, Revista Aguaita, ${ }^{\circ}$ 12, Cartagena, Observatorio del Caribe Colombiano, pp. 15-20.

Abello Vives, A. (1983). "Muelle de Puerto Colombia", 50 días que cambiaron la historia de Colombia. Bogotá: Semana-Planeta.

Ávila Domínguez, F. (2008). "La representación de Cartagena de Indias en el discurso turístico", Cuaderno de Trabajo, n² 2 , México, Proyecto AFRODESC, pp. 2-120.

Bourdieu, P. \& Wacquant, J. D. (1995). Respuestas. Por una antropología reflexiva. México: Grijalbo.

Bourdieu, P. (1990). Sociología y Cultura. México: Grijalbo. (1997). Las reglas del arte. Génesis y estructura del campo literario, Barcelona: Anagrama

Burke, P. (2005). Visto y no visto. El uso de la imagen como documento histórico. Barcelona: Crítica.

Castillo, C. (2001). “Transformaciones de la identidad juvenil: 'las tribus urbanas' ", Boletín, no 3, Fundación Puertas Abiertas, en: http:// www.puertasabiertas.com.ar/descargas/tribusurbanas.pdf.

Carrillo Romero, H. (2011). Ocultar la pobreza para inventar el paraíso: la construcción histórica de la imagen turística de Cartagena, 1943- 
1978. Tesis de pregrado en Historia, Cartagena, Universidad de Cartagena.

Conde Calderón, J. (1994). “Autonomía y rivalidades entre poblaciones en la provincia de Cartagena, 1810-1815", Revista Historia y Cultura, ${ }^{\circ}$ 3, Cartagena, Universidad de Cartagena, pp. 69-78.

Cunin, E. (2007). "El turismo en Cartagena. Vendo, luego excluyo", Revista Noventaynueve, no 7, Cartagena, pp. 24-39.

(1999). "Relaciones interétnicas, procesos de identificación y espacio urbano en Cartagena", IV Seminario Internacional de Estudios del Caribe. Memorias, Bogotá, Instituto Internacional de Estudios del Caribe, Universidad de Cartagena, Universidad del Atlántico, pp. 119-133.

(2003). Identidades a flor de piel. Lo "negro" entre apariencias y pertenencias: categorías raciales y mestizaje en Cartagena. Bogotá: Instituto Colombiano de Antropología e Historia, Universidad de los Andes, Instituto Francés de Estudios Andinos, Observatorio del Caribe Colombiano.

De Ávila Pertuz, O. (2008). Políticas urbanas y exclusión social en Cartagena: el caso de Chambacú. 1956-1971. Tesis de pregrado en Historia, Cartagena, Universidad de Cartagena.

García Canclini, N. (1990). Culturas híbridas. Estrategias para entrar y salir de la modernidad. México: Grijalbo.

Giaimo Chávez, S. (2000). "Cartagena, sobrellevando la crisis" (relatora). En Abello Vives, A. \& Giaimo Chávez, S. (Comp). Poblamiento y ciudades del Caribe colombiano. Bogotá: Observatorio del Caribe Colombiano, FONADE.

Grimson, A (2001). Interculturalidad y comunicación. Bogotá: Norma,

Guerrero Palencia, L. (2008). Imaginarios urbanos en Cartagena: visiones y proyectos de ciudad 1910-1925. Tesis de pregrado en Historia, Cartagena, Universidad de Cartagena.

Lacarrieu, M. (2007). “La 'insoportable levedad' de lo urbano”, Revista Eure, vol. XXXIII, n 99, pp. 47-64.

Lizcano Angarita, M. \& David Daccarett, K. (2004). "Valoración del patrimonio arquitectónico mudéjar y neomudéjar del Caribe Colombiano", Revista Aguaita, ${ }^{\circ}$ 11. Cartagena, Observatorio del Caribe Colombiano, pp. 75-84.

López Montaño, C. \& Abello Vives, A. (1998). El Caribe colombiano. La realidad regional al final del siglo XX. Bogotá: Departamento Nacional de Planeación, Observatorio del Caribe Colombiano.

Marco Dorta, E. (1951). Cartagena de Indias. Puerto y plaza fuerte. Bogotá: Fondo Cultural Cafetero.

Meisel Roca, A. (1999). “Cartagena 1900-1950. A remolque de la economía nacional”, Cuadernos de historia económica y empresarial, $\mathrm{n}^{\circ} 4$, Cartagena, Centro de Investigaciones Económicas del Caribe Colombiano, Banco de la República. 
Múnera Cavadía, A. (1998). El fracaso de la nación. Región, clase y raza en el Caribe colombiano (1717-1810). Bogotá: Banco de la República, El Áncora Editores.

Ortiz, R. (2000). Modernidad y espacio. Benjamin en París. Bogotá: Norma.

Palou Rubio, S. (2006). "La ciudad fingida. Imágenes y promoción del turismo en Barcelona. Perspectiva histórica y cuestiones del presente", Redmarka-Ciecid, Universidad de A Coruña, vol. I, n 3 , pp.79-104.

Pérez, G. \& Salazar Mejía, I. (2007). "La pobreza en Cartagena: un análisis por barrios", Documentos de trabajo sobre economía regional, $\mathrm{n}^{\circ}$ 94, Cartagena, Banco de la República.

Reguillo Cruz, R. (2000). Emergencia de culturas juveniles. Estrategias del desencanto. Bogotá: Norma.

Román Romero, R. (2001). "Memoria y contramemoria: El uso público de la historia en Cartagena”. En Buenahora, G.; Ortiz, J.; Quiroz, P.; \& Román, R. Desorden en la plaza. Modernización y memoria urbana en Cartagena, Cartagena: Instituto Distrital de Cultura, pp. 7-32.

Serrano Álvarez, J. M. (2004). "La importancia de Tierra Firme en el sistema defensivo americano, 1700-1788”, Revista Aguaita, n 10, Cartagena, Observatorio del Caribe Colombiano.

Sparrow, M. (2011). "El tren de las murallas". En Bicentenario Cartagena de Indias, 1811-2011, II. Bogotá: Alcaldía de Cartagena, Revista Semana.

Téllez Iregui, G. (2002). Pierre Bourdieu. Conceptos básicos y construcción socioeducativa. Bogotá: Universidad Pedagógica Nacional.

Vidal, Claudia (1997). Los inicios de la actividad turística en Cartagena, 1900 1950". Tesis de pregrado en Historia, Cartagena, Universidad de Cartagena.

Vizcarra, F. (2002). “Premisas y conceptos básicos en la sociología de Pierre Bourdieu", Revista Estudios sobre las Culturas Contemporáneas, vol. VIII, n¹6, pp. 55-68. 